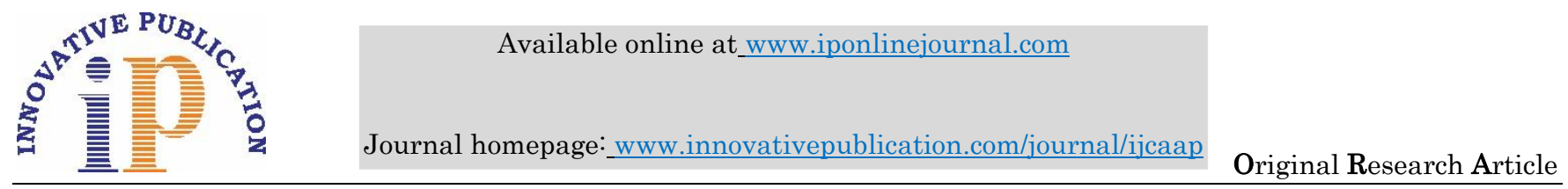

\title{
Rationale use of antiepileptic drugs in patients with epilepsy at a tertiary care hospital
}

\author{
Dwajani $\mathrm{S}^{1^{*}}$, Nayanashree $\mathrm{V}^{2}$, Mrudula $\mathrm{S}^{3}$, Krishna $\mathbf{M V}^{4}$ \\ ${ }^{\mathbf{1}}$ Assistant Professor, ${ }^{\mathbf{2}, 3}$ III year, MBBS Student, ${ }^{4}$ Professor and HOD, ${ }^{\mathbf{1}}$ Dept. of Pharmacology / Senior Research Associate, Central \\ research Lab, ${ }^{4}$ Dept. of General Medicine, ${ }^{1-4}$ Rajarajeswari Medical College and Hospital, Kambipura, Mysore road, Bangalore, Karnataka, \\ India
}

\begin{abstract}
Epileptic convulsions have negative consequences on patient's psychological and social life like relationship, education and employment. Seizure which are uncontrolled, are always associated with poor quality of life, physical and psychosocial morbidity, increased risk of sudden unexpected death. Hence, it is important and becomes mandatory to treat epilepsy with appropriate antiepileptic drugs (AEDs) as soon as the patient reports with more than one documented or witnessed seizure. Our purpose was to investigate the use of antiepileptic drugs in epilepsy, changes in prescription patterns, exposure to specific drugs, combination of drugs, and to quantify the use of antiepileptic drugs (AEDs) in epilepsy at a tertiary care hospital. A Total of 105 patients were recruited, majority were male and between 18-25 yrs. and belonged to upper lower class. $80 \%$ were diagnosed with GTCS. Majority were on monotheraphy and phenytoin was most commonly used antiepileptic drug for the treatment of epilepsy. The drugs prescribed are mainly from older AEDs. Selection of AEDs is based on their known efficacy for specific seizure. Such studies was help in modifying the prescription guidelines as they have an important role in making rationale prescription and to see if it's being followed at tertiary care centres.
\end{abstract}

Keywords: Epilepsy, Antiepileptic drugs, Rational drug use, Drug utilization.

\section{Introduction}

Epilepsy affects 0.5 to $1 \%$ of the population that is around 50 million people worldwide. ${ }^{1}$ It is considered as one of the most common neurological disorders characterized by spontaneously recurrent seizures. Epileptic seizure is transient, occurrence of signs and symptoms are due to abnormal excessive synchronous activity in brain. ${ }^{2}$ Epileptic convulsions have negative consequences on patient's psychological and social life like relationship, education and employment. Seizure which are uncontrolled, are always associated with poor quality of life, physical and psychosocial morbidity, increased risk of sudden unexpected death. Hence, it is important and becomes mandatory to treat epilepsy with appropriate antiepileptic drugs (AEDs) as soon as the patient reports with more than one documented or witnessed seizure. ${ }^{3}$

The goal of treatment is always to maintain a normal life style of the patient through complete seizure control with no or very less side effects. The causes of the seizure may be idiopathic or could be due to trauma, infection, or because of the presence of malformation or mass lesion. Hence, there is progressive damage, hyper excitability and convulsions can occur. ${ }^{4}$ Management of epilepsy is difficult at rural and semi urban as they are still primitive due to unavailability of neurospecialists. A large number of antiepileptic drugs are presently available for the treatment of epilepsy and important to know the prescribing pattern of AEDs.

The interest in drug utilization studies began in the early $1960 \mathrm{~s},{ }^{5}$ the importance has been increasing since then as the increase in marketing of new drugs had improved drastically, while wide variation in the pattern of drug treatment, increased concern about adverse effects and regarding the cost of drugs. ${ }^{6,7}$

Hence we intended to study the use of antiepileptic drugs in epilepsy, changes in prescription patterns, exposure to specific drugs, combination of drugs, and to quantify the use of antiepileptic drugs (AEDs) in epilepsy at a tertiary care hospital.

\section{Materials and Methods}

After obtaining ethical committee clearance the study was conducted at a tertiary care hospital in Bangalore. It was a prospective, observational study. We recruited patients with epilepsy visiting outpatient and inpatients department of General medicine. Patients above 18 years of both the genders receiving AEDs either conventional or newer drugs were included. Patients with major neurologic disabilities such as mental retardation, aphasia, or motor deficits, patient with secondary epilepsy, pregnant, lactating women were excluded from this study.

Data was collected using Case Record Form [CRF]. Demographic data was collected as per Kuppuswamy scale ${ }^{8}$ which is considered as standard method for analyzing socioeconomic status. Disease characteristics like type of epilepsy, age of onset and duration of seizure, time since last attack, frequency of seizures, family history of epilepsy, any co morbid conditions were noted. Treatment details like monotherapy/polytherapy, dose, and duration of treatment, alternative systems of medications, and treatment for co

*Corresponding Author: Dwajani S, Dept. of Pharmacology / Senior Research Associate, Central research Lab, Rajarajeswari Medical College and Hospital, Kambipura, Mysore road, Bangalore, Karnataka, India

Email: dwajani@gmail.com

http://doi.org/10.18231/j.ijcaap.2019.020 
morbid conditions were noted.Adverse event profile was also recorded. All the investigational reports like biochemical, EEG, CT/MRI reports were collected if available.

\section{Results}

A Total of 105 patients were recruited in the study. We noticed male predominance of $60.9 \%(\mathrm{n}=64)$ compared to females $39 \%(n=41)$. Majority $27 \%(n=29)$, of the patients were in the age group of $18-25$ years (Fig. 1)

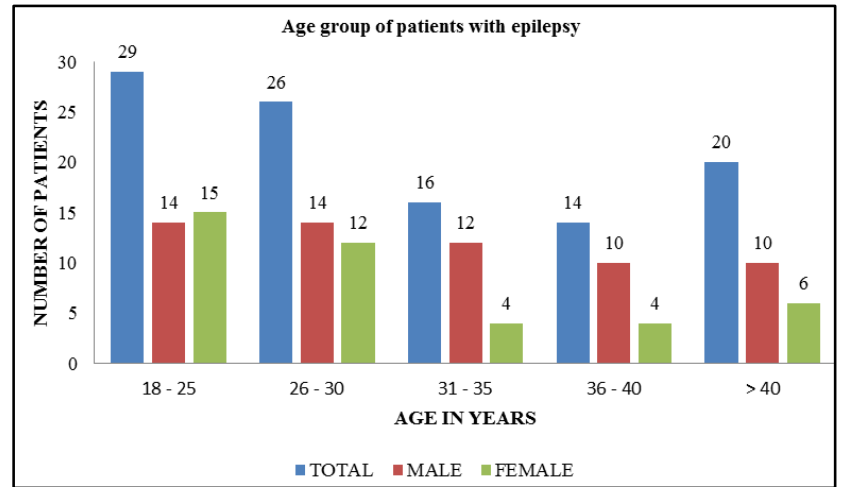

Fig. 1: Age group of patients with epilepsy

Among 105 patients, $62 \% \quad(\mathrm{n}=66)$ were from rural background, while $37 \% \quad(\mathrm{n}=39)$ were from urban background. $30 \%(n=32)$ of patients completed their high school studies.On assessing the occupation status 33\% $(n=35)$ of patients were skilled workers. (Fig. 2). As per modified Kuppuswamy scale, ${ }^{8}$ we analyzed the socioeconomic status of these patients and observed that majority of them belonged to Upper lower class $46 \%(\mathrm{n}=48)$. (Fig. 3)

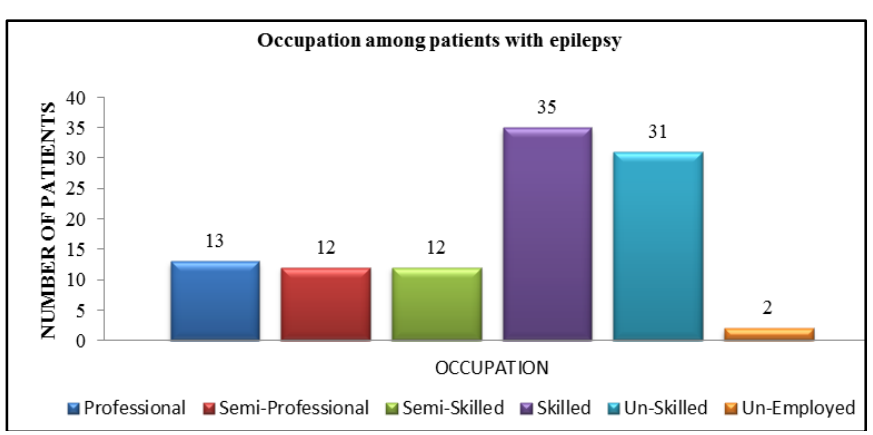

Fig. 2: Occupation of patients with epilepsy

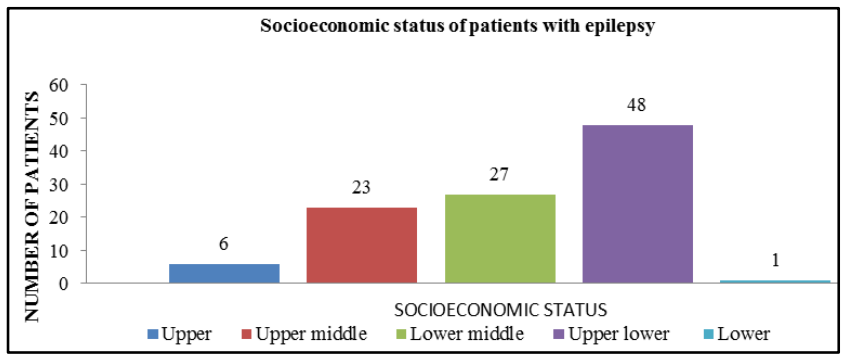

Fig. 3: Socio economic status of patients with epilepsy according to kuppuswamy scale
On assessing the habits of patients, it was found that majority were non smokers $77 \%(\mathrm{n}=81)$ and non alcoholics $86 \%$ ( $\mathrm{n}=90$ ). Amongst the alcoholics, the following details were obtained regarding the alcohol consumption (Fig. 4)

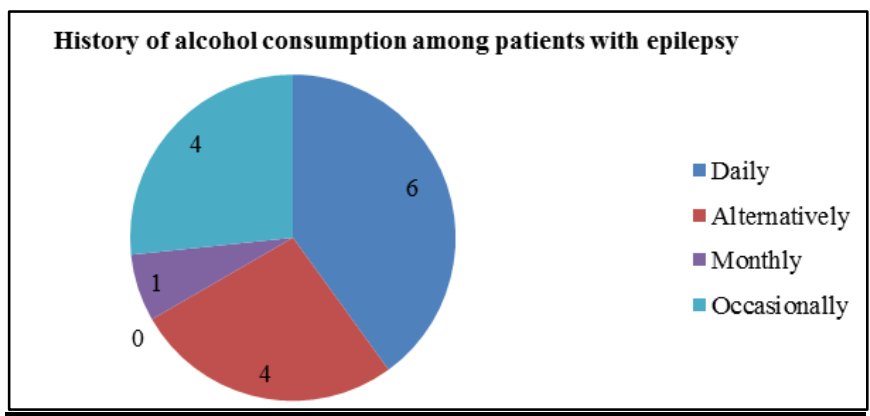

Fig. 4: History of seizures among patients with epilepsy

With connection to the initiation of AED treatment, 63\% $(n=66)$ of patients began treatment with AEDs immediately within 3 months of attack (Table 1)

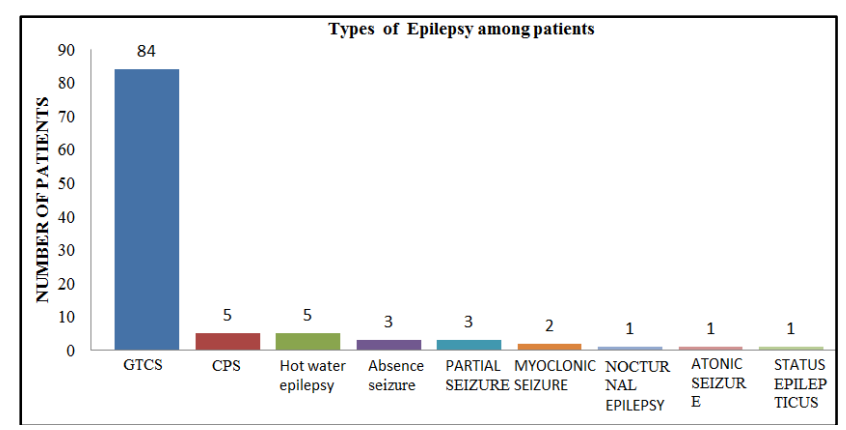

Fig. 5: Type of seizures among patients with epilepsy

Among the 105 patients, majority $80 \% \quad(n=84)$ were diagnosed with GTCS (Generalized tonic clonic seizures).Other types of seizures were less common. (Fig. 5)

Table 1: Time taken to initiate treatment after first attack of seizure

\begin{tabular}{|c|c|c|}
\hline S. No. & Time duration & $\begin{array}{c}\text { Number of } \\
\text { patients }\end{array}$ \\
\hline 1. & Within 3 months of attack & 66 \\
\hline 2. & 3-6 months of attack & 03 \\
\hline 3. & 6 months-1year of attack & 10 \\
\hline 4. & 1-2years of attack & 04 \\
\hline 5. & 2-3years of attack & 10 \\
\hline 6. & >3years of attack & 12 \\
\hline
\end{tabular}

On assessing the family history of seizures, $29 \%(\mathrm{n}=31)$ reported with positive cases of epilepsy within their near/ dear family members and were on treatment / treated with AEDS. Among 105 patients under study, it was found that about $22 \%(n=23)$ of them had co morbid conditions like hypertension, diabetes mellitus. Most of them $87 \%(\mathrm{n}=91)$ did not sustain any past head injury. 
With regards to the treatment with antiepileptic drugs, majority of the patients $88 \% \quad(n=92)$ received AED monotherapy, among which phenytoin $34 \%(\mathrm{n}=37)$ was used more commonly prescribed, While $10 \% \quad(\mathrm{n}=11)$ received dual therapy and only $2 \% \quad(n=2)$ received polytherapy. Maximum $78 \%(\mathrm{n}=82)$ were prescribed with older AEDs, followed by $17 \%(\mathrm{n}=18)$ received newer AEDs and $5 \%(n=5)$ received a combination of older and newer AEDs. (Fig. 6)

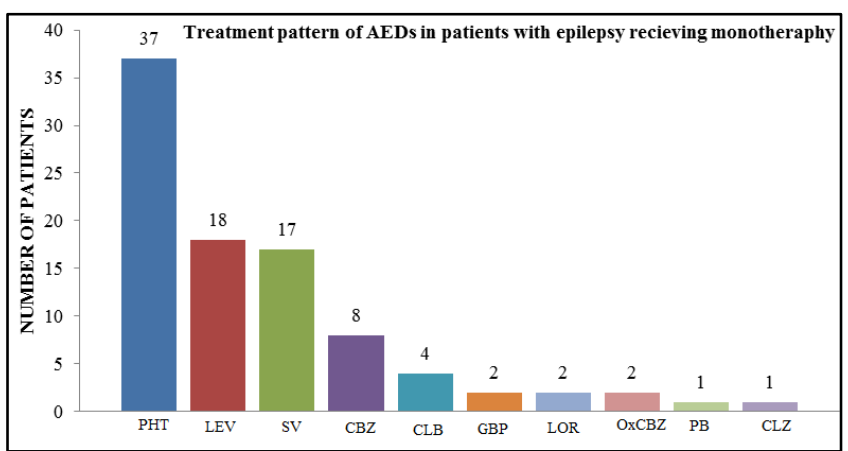

Fig. 6: Treatment pattern of AEDs in patients with epilepsy receiving monotherapy

Table 2: Dual and polytherapy drugs received in patients with epilepsy

\begin{tabular}{|c|l|c|}
\hline $\begin{array}{c}\text { S. } \\
\text { No. }\end{array}$ & \multicolumn{1}{|c|}{ Aeds combination received } & $\begin{array}{c}\text { Number of } \\
\text { patients }\end{array}$ \\
\hline 1. & Phenytoin+Clobazam & 01 \\
\hline 2. & Phenytoin+Lorazepam & 01 \\
\hline 3. & Phenobarbitone+Carbamazepine & 01 \\
\hline 4. & Levetiracetam+Phenytoin & 02 \\
\hline 5. & Levetiracetam+Clobazam & 01 \\
\hline 6. & Phenobarbitone+Levetiracetam & 01 \\
\hline 7. & Sodium valproate+Phenytoin & 01 \\
\hline 8 & Phenytoin+Carbamazepine & 02 \\
\hline 9. & $\begin{array}{l}\text { Sodium valproate +Levetiracetam+ } \\
\text { Clobazam+ Phenytoin }\end{array}$ & 01 \\
\hline 10. & $\begin{array}{l}\text { Sodium valproate + Carbamazepine } \\
\text { + Levetiracetam }\end{array}$ & 01 \\
\hline
\end{tabular}

Only $6 \%(\mathrm{n}=6)$ of the patients complained of adverse effects due to AED therapy amongst which drowsiness was the commonest complain. EEG was done as a diagnostic tool in $90 \%(\mathrm{n}=94)$ of the patients, on assessing the results $18 \%$ $(\mathrm{n}=19)$ patients had abnormal EEG . CT and MRI were done in $72 \%(n=76)$ of the patients amongst which $28 \%(n=21)$ were found to have abnormal CT and MRI.

\section{Discussion}

In our study, maximum patients receiving AEDs were males and belonged to age group between 18-25 years which was similar to the study done by Ranjana Gurumurthy and her colleagues $^{9}(2017)$. Maximum number of patients belonged to rural area in our study which was in contrast to study done by Abhik Sinha and his colleagues ${ }^{10}$ (2012) which had urban predominance. This could be due to the location of our hospital which is towards the rural area where majority of the patients come from surrounding region. As per modified Kuppuswamy scale, ${ }^{8}$ when we analyzed the socioeconomic status of these patients, found that majority of them belonged to upper lower class which is $46 \%$ $(\mathrm{n}=48)$ while study done by Abhik $\sinh ^{10}(2012)$ did not find any association.

On assessing the occupation status, we observed that majority of patients were under the category of skilled workers. This is in contrast to findings of Ranjana Gurumurthy and her colleagues ${ }^{9}$ (2017) where majority were unemployed. In a study done by Barbara A Dworetzky $^{12}$ (2018) most of the patients were non smokers which was similar to our findings. On assessing type of epilepsy, GTCS was the most frequent type of epilepsy seen in our study which is similar to findings of Nethmie Chandrarathna ${ }^{11}$ (2019). With respect to family history of seizures, $29 \%[\mathrm{n}=31]$ of patients reported with positive cases of epilepsy within their near/dear family members and were on treatment/treated with AEDs which was similar to the study done by Nilofer shams and his colleagues ${ }^{12}(2018)$ who observed family history of seizures in $18.9 \%$ of cases. This is because if both parents /either of the parents are epileptic, then the risk of child getting epilepsy is more. On assessing co-morbid conditions of seizures, it was found that about $22 \%(\mathrm{n}=23)$ of them had co-morbid conditions like hypertension,diabetic mellitus. Majority of the patients with epilepsy in our study $87 \%$ ( $\mathrm{n}=91$ ) did not sustain any past head injury which is in contrast to study done by Gizachew Kassahun ${ }^{13}$ (2018) and his colleagues,

On assessing treatment pattern of seizures, we found that, $34 \%(\mathrm{n}=37)$ were prescribed phenytoin and prescribed as monotherapy. While, $10 \%(\mathrm{n}=11)$ received dual therapy and only $2 \%(\mathrm{n}=2)$ recieved polytherapy. Maximum $78 \%$ $(n=82)$ were prescribed with older AEDs, followed by $17 \%$ $(n=18)$ recieved newer AEDs and 5\% (n=5) received a combination of older and newer AEDs. This is in contrast to findings of Ancy M Das ${ }^{14}(2018)$ where $51 \%$ were on polytherapy and remaining on monotherapy.

On assessing EEG about 94 patients underwent EEG and found that $18 \%(\mathrm{n}=19)$ patients had abnormal EEG. A study done by Panagariya A and his colleagues ${ }^{15}(2019)$, found that EEG was abnormal in 58.9\%, which was higher than our findings. On assessing the CT scan of patients with epilepsy, about 76 patients underwent CT and MRI amongst which $28 \%(n=21)$ were found to have abnormal CT and MRI.

\section{Conclusion}

Maximum patients were male and belonged to age group between 18-25years. Monotherapy was most frequent used in all type of epileptic seizures. The drugs prescribed are mainly from older AEDs. Generalized seizures were prominent and reported by majority of patients. Selection of AEDs is based on their known efficacy for specific seizure. Monotherapy with Phenytoin was most frequently used. 
Such studies was help in modifying the prescription guidelines as they have an important role in making rationale prescription and to see if it's being followed at tertiary care centres.

\section{Source of Funding}

None.

\section{Conflict of Interest}

None.

\section{References}

1. De Boer HM, M ula M, Sander JW. The Global Burden and Stigma of Epilepsy, Epilepsy Behav. 2008;12:540-6.

2. Fisher RS, Boas WvE, Blume W, Elger C, Genton P, Lee P et al. Epileptic Seizures and Epilesy Definition Proposed by ILEA and IBE. Epilesia 2005;46(4):470-2.

3. Brodie MJ. Medical therapy of epilepsy: When to initiate treatment and when to combine? J Neurol 2005;252:125-30.

4. Dichter MA. Emerging Concepts in the pathogenesis of Epilepsy and Epileptogenesis. Arch Neurol 2009; 66:443-7.

5. Strom BL. Pharmacoepidemiology. Fourth ed: John Wiley \& Sons, Ltd 2005.

6. Andersen M. Is it possible to measure prescribing quality using only prescription data? Basic Clin Pharmacol Toxicol 2006;98:314-9.

7. Wettermark B, Hammar N, MichaelFored C, Leimanis A, Otterblad Olausson P, Bergman U, et al. The new Swedish Prescribed Drug Register--opportunities for pharmacoepidemiological research and experience from the first six months. Pharmacoepidemiol Drug Saf 2007; 16:726-35
8. Morisky De, Green Lw, Levine Dm. Concurrent and predictive validity of a self-reported measure of medication adherence. Med Care 1986;24(1):67-74.

9. Gurumurthy R, Chanda K, Sarma G - An evaluation of factors affecting adherence to anti- epileptic drugs in patients with epilepsy - a cross sectional study. Singapore Med J 2017; 58(2):98-102.

10. Sinha A, Mallik S, Dasgupta S - Health care seeking Behaviours of patients with epileptic seizuredisorders attending a tertiary care hospital, Kolkata. Indian J Community Med 2012;37(1):25-9.

11. Chandrarathna N, Parida A, Manju V, Uppor, Adiha S, Drug utilization studies-in a tertiary care hospital. Biomed Pharmacol J 2019;12(2).

12. Shams N, Hussain SF, Mohsinullahkahn, Ansari JA, Khan $\mathrm{M}$, A prospective observational study on drug utilization of antiepileptic medications used during treatment at a tertiary care teaching hospital. Int J Adv Pharm Med Bioallied Sci 2018:7(1):1-8.

13. Kassahun G, Moges G, Demessie Y, Assessment of patients Adherence to anti-epileptic medications at Dessie Referral Hospital, Chronic Follow-up, South Wollo, Amhara Region, North East Ethiopia. Neurol Res Int 2018:5109615.

14. AncyMDas, Ramamoorthy L, Wadwekar V, Barriers of drug adherence among patients with epilepsy in tertiary care hospital, South India. J Caring Sci 2018;7(4);177-81.

15. Panagariya A - Quantitative phramaco-electro encephalographyin Antiepileptic drug research. CNS Drugs 2018;32(9): 839-48.

How to cite this article: Dwajani $\mathrm{S}$, Nayanashree $\mathrm{V}$, Mrudula S, Krishna MV. Rationale use of antiepileptic drugs in patients with epilepsy at a tertiary care hospital. Int J Comprehensive Adv Pharmacol 2019;4(3):96-9. 